\title{
Construction of Mathematical Relationships and Software Implementation of a Simulation Model of the Behavior of Components of the Musculoskeletal System of a Person
}

\author{
Alena Nikonova \\ Department of Computer Science and Robotics \\ Ufa State Aviation Technical University \\ Ufa, Russia \\ gil17011995@gmail.com
}

\author{
Rashit Nasyrov \\ Department of Computer Science and Robotics \\ Ufa State Aviation Technical University \\ Ufa, Russia \\ nrash@yandex.ru
}

\begin{abstract}
The article is devoted to the creation of a software tool for modelling the behaviour of the components of the musculoskeletal system using the example of segments of the spine using the Orne-Liu formalism. A system of differential equations is written that describes the movement of the components of the spine in the sagittal plane (up-down, forward-backward, rotation).A tool has been obtained that allows one to study the evolution of the centres of three vertebrae interconnected when applying standard exposure. The data obtained during the calculations can then be applied to the already developed three-dimensional model of the thoracic spine. In the future, a similar mathematical model can be applied to the entire spine, since the initial data for the cervical, thoracic and lumbar spine are calculated and can be used.
\end{abstract}

Keywords-spine, vertebra, mathematical modeling, modeling

\section{RELEVANCE}

The functional state of the spine as the main component of the musculoskeletal system of a person is significant not only from a biomechanical point of view, but also from the point of view of maintaining the quality of life. Various types of violation of the integrity of the spine, the degradation of its functions quite often lead to the development of subcritical and critical states of human health. In this regard, the development of research methods and modeling of the spine as a complex system, of course, is relevant.

Since the spine is a complex system with complex behavior under various types of load, to understand the mechanisms of behavior, it is necessary to develop a mathematical model of the spine, which will be based on existing mathematical models.

\section{StATUS OF THE ISSUE}

A fairly large number of works are devoted to research in the field of biomechanics and three-dimensional modeling, which is presented in the published periodic literature. These works are devoted to the study of the following issues: mathematical modeling of biomechanics, three-dimensional modeling of various parts of the spine. These works can be divided into topics of tasks that they solve and issues that they consider.
Note that the largest number of works is devoted to solving three-dimensional modeling problems. For example, an article by Boonbrahm P., Sewata L., Boonbrahm S. [1] discusses the approach of translating two-dimensional data into a three-dimensional model. In an article authored by Bennani H., McCane B., Cornwall J. [2], a set of threedimensional data was created for the human lumbar vertebrae, that is, they model the vertebrae of the lumbar spine with real data collected for further study. The work of Rehm J., Germann T. et al. [3] is devoted to a retrospective assessment of the reproducibility and reliability of the interoperator 3D reconstruction of the full spine in patients with adolescent idiopathic scoliosis. In an article by Aroeira R.M.C., Pertence A.E.M. et al. [4] created a threedimensional geometric model of the vertebrae of the thoracic spine (T5-T10) using two anatomical images of the T6 vertebra (side and top). The article by Picazo M.L., Baro A. et al. [5] focuses on a 3-D subject evaluation of the shape and density of the lumbar spine from one anteroposterior image. Authored by Hollenbeck J.F.M., Cain C.M. et al. [6] developed a set of three-dimensional statistical models for characterizing anatomical variability in the lumbar spine. The patent [7] is devoted to the diagnosis of scoliosis using a 3D scanner. The work of Nikonova A.I. [8] is devoted to the construction of a three-dimensional model of the thoracic spine.

A slightly smaller number of works is devoted to the consideration of the problem of mathematical modeling. The authors of Voinea G.-D., Butnariu S., Mogan G. [9] presented a mathematical model that can be used for virtual reconstruction of the human spine posture. Guan W., Sun Y. et al. [10] presented a mathematical model of the relationship between strength and displacement of the intervertebral disc. The article by Meyer F., Humm J., Purushothaman Y., Willinger R., Pintar F.A., Yoganandan N. [11] uses the finite element method to construct a model of forces and moments in the spine. A similar problem is solved by Fan R.X., Liu, J., Liu J., Wang W.J. [12]. The work of Pourahmadi M.R., Takamjani I. et al. [13] is devoted to a detailed review of kinematic models of the spine.

The third area of research is the development of models, methods, devices and systems for assessing the functional state of the spine. We give patents as an example [14, 15]. The works of Bakusov L. M., Nasyrov R. V., Minasov T. 
[16]; Bayoglu R., Geeraedts L. et al. [17]; Badamshin R.A., Bakusov L.M., Nasyrov R.V., Minasov T.B. [18] are devoted to the development of models and methods for assessing the biomechanical characteristics of the spine.

Articles Jakubicek R., Chmelik J., Jan J., Ourednicek P., Lambert L., Gavelli G. [19] and Buharbaeva L. Ya., Nasyrov R.V., Tiunov I.S. [20] discuss the development and application of CAD systems for spinal modelling.

It should also be noted that the theoretical foundations of research are discussed in [21,22,23,24].

An essential fact is that in the above studies either a three-dimensional model or a mathematical one is created, but not both models at the same time.

\section{STATEMENT OF THE PROBLEM}

The aim of this work is to build mathematical relationships and create a software tool for modeling the behavior of the spinal segment based on the known relationships of the Orne-Liu mathematical model.

To do this, it is necessary to solve the following problems.

1) Build a structural diagram of the selected area of the spine as a component of the musculoskeletal system.

2) Write down a system of differential equations corresponding to the constructed block diagram.

3) Choose a mathematical modeling environment for simulating behavior based on the constructed system of equations.

4) Implement a software tool within the framework of a mathematical modeling environment and conduct a simulation experiment.

\section{PROPOSED APPROACH}

To solve the problems posed, the authors used the approach proposed by Orne and Liu and described in [25]. The choice of this model was due to the fact that its appearance was a qualitative leap in the field of studying the spine from a mathematical point of view, as well as the fact that almost all modern models of this type are, to some extent, its modifications. In the framework of this approach, the structure of the spine in the sagittal plane is considered. A single element of the model consists of a completely solid vertebra and a weightless deformable intervertebral disc. Each ith vertebra has two translational degrees of freedom $u$ and $w$ and one rotational $\phi$.

In accordance with the adopted model, we will further compose a system of differential equations describing the behavior of each vertebra in the spine. To illustrate the approach used and the resulting solution, it is sufficient to use the three upper vertebrae of the thoracic spine (T1, T2 and T3). Note that in such a system for each component seven equations will be used - three first order, four second order. A general view of the model for the selected three vertebrae is shown in Figure 1.

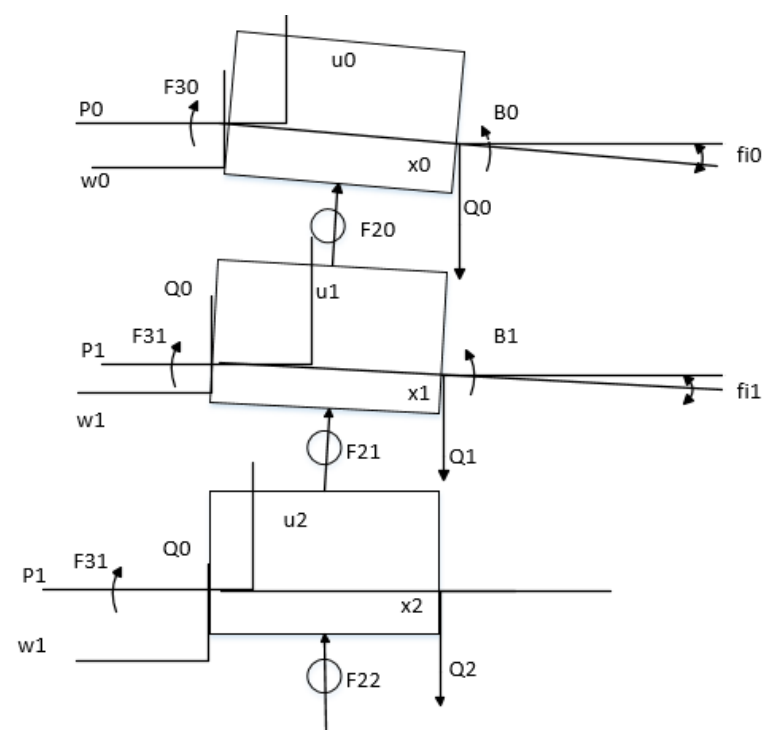

Fig. 1. Structural diagram of three vertebrae in accordance with the representation of Orne-Liu

In Figure 1, the following notation is used: $u$ is the coordinate of the initial configuration of the shift back and forth; $w$ is the coordinate of the initial configuration of the shift up and down; $\phi$ is the coordinate of the initial configuration of the rotation of the vertebra; $x$ is the coordinate of the middle of the vertebra; $F 2$ - longitudinal force; $F 3$ - rotational force; $B$ - support reaction to bending force; $P$ is the projection of the resultant forces on the horizontal axis; $Q$ is the projection of the resultant forces on the vertical axis

\section{FORMATION OF A SYSTEM OF EQUATIONS}

Next, we present a system of seven equations written for each of their selected vertebrae.

The system of equations for the 1st vertebra:

$$
\left\{\begin{array}{c}
\frac{d u_{1}}{d t}=\varepsilon_{1} \\
\frac{d w_{1}}{d t}=\lambda_{1} \\
\frac{d \phi_{1}}{d t}=\omega_{1} \\
\frac{d \varepsilon_{1}}{d t}=\frac{1}{m_{1}}\left(Q_{1}-Q_{0}\right)-c_{11} \omega_{1}^{2}+c_{21} \frac{d \omega_{1}}{d t} \\
\frac{d \lambda_{1}}{d t}=\frac{1}{m_{1}}\left(P_{1}-P_{0}\right)-c_{21} \omega_{1}^{2}-c_{11} \frac{d \omega_{1}}{d t} \\
\frac{d \omega_{1}}{d t}=\frac{1}{j_{1}}\left[\left(F_{31}-B_{1}\right)-c_{21} Q_{0}+c_{31} Q_{1}+c_{11} P_{0}-c_{41} P_{1}\right] \\
\frac{d F_{2}}{d t}=\frac{1}{p_{1}}\left[-F_{2}+\frac{A_{0}}{g_{0}}\left(q_{0} \delta_{1}+q_{1} \delta_{1}\right)\right]
\end{array}\right.
$$


The system of equations for the 2st vertebra:

$$
\left\{\begin{array}{c}
\frac{d u_{2}}{d t}=\varepsilon_{2} \\
\frac{d w_{2}}{d t}=\lambda_{2} \\
\frac{d \phi_{2}}{d t}=\omega_{2} \\
\frac{d \varepsilon_{2}}{d t}=\frac{1}{m_{2}}\left(Q_{2}-Q_{1}\right)-c_{12} \omega_{2}^{2}+c_{22} \frac{d \omega_{2}}{d t} \\
\frac{d \lambda_{2}}{d t}=\frac{1}{m_{2}}\left(P_{2}-P_{1}\right)-c_{22} \omega_{2}^{2}-c_{12} \frac{d \omega_{2}}{d t} \\
\frac{d \omega_{2}}{d t}=\frac{1}{j_{2}}\left[\left(F_{32}-B_{2}\right)-c_{22} Q_{1}+c_{32} Q_{2}+c_{12} P_{1}-c_{42} P_{2}\right] \\
\frac{d F_{22}}{d t}=\frac{1}{p_{2}}\left[-F_{22}+\frac{A_{1}}{g_{1}}\left(q_{0} \delta_{2}+q_{1} \delta_{2}\right)\right]
\end{array}\right.
$$

The system of equations for the 3 st vertebra:

$$
\left\{\begin{array}{c}
\frac{d u_{3}}{d t}=\varepsilon_{3} \\
\frac{d w_{3}}{d t}=\lambda_{3} \\
\frac{d \phi_{3}}{d t}=\omega_{3} \\
\frac{d \varepsilon_{3}}{d t}=\frac{1}{m_{3}}\left(Q_{3}-Q_{2}\right)-c_{13} \omega_{3}^{2}+c_{23} \frac{d \omega_{3}}{d t} \\
\frac{d \lambda_{3}}{d t}=\frac{1}{m_{3}}\left(P_{3}-P_{2}\right)-c_{23} \omega_{3}^{2}-c_{13} \frac{d \omega_{3}}{d t} \\
\frac{1}{d t}=\frac{1}{j_{3}}\left[\left(F_{33}-B_{3}\right)-c_{23} Q_{2}+c_{33} Q_{3}+c_{13} P_{2}-c_{43} P_{3}\right] \\
\frac{d F_{23}}{d t}=\frac{1}{p_{3}}\left[-F_{23}+\frac{A_{2}}{g_{2}}\left(q_{6} \delta_{3}+q_{6} \delta_{3}\right)\right]
\end{array}\right.
$$

Three systems of equations are connected through $P$ (the projection of the resultant forces on the horizontal axis) and $Q$ (the projection of the resultant forces on the vertical axis).

When writing the system of equations, we used the notation corresponding to Figure 1, where the variable $\mathrm{c}$ is the coefficient associated with the angle of inclination. Thus, for a subset of the three upper vertebrae of the thoracic spine, a system of 21 differential equations is obtained in which both variables and constants with set values corresponding to each of the vertebrae are used.

\section{THE CHOICE OF MEANS OF IMPLEMENTATION}

Despite the fact that there are many different programs

\begin{tabular}{|c|c|c|}
\hline Method & Description & Explanation \\
\hline ode23 & $\begin{array}{l}\text { 2th and 4th Order } \\
\text { Runge-Kutta One- } \\
\text { Step Explicit } \\
\text { Methods }\end{array}$ & $\begin{array}{l}\text { With moderate } \\
\text { rigidity of the ODE } \\
\text { system and low } \\
\text { accuracy } \\
\text { requirements, this } \\
\text { method can give a } \\
\text { gain in solution } \\
\text { speed }\end{array}$ \\
\hline ode45 & $\begin{array}{l}\text { 4th and 5th Order } \\
\text { Runge-Kutta One- } \\
\text { Step Explicit } \\
\text { Methods }\end{array}$ & $\begin{array}{l}\text { This is the classic } \\
\text { method } \\
\text { recommended for } \\
\text { initial testing of a } \\
\text { solution. In many } \\
\text { cases, it gives good } \\
\text { results }\end{array}$ \\
\hline ode113 & $\begin{array}{l}\text { Variable-order } \\
\text { Adams-Bashworth- } \\
\text { Multon method }\end{array}$ & $\begin{array}{l}\text { This is an adaptive } \\
\text { method that can } \\
\text { provide high } \\
\text { precision solutions }\end{array}$ \\
\hline
\end{tabular}
for mathematical modelling [26], for the initial stage and in order to solve the system of differential equations, it was decided to use the mathematical modelling environment Matlab.

For Matlab it is possible to create special toolboxes, expanding its functionality [27]. Toolboxes are collections of functions and objects written in the Matlab language for solving a specific class of problems. Mathworks supplies tool kits that are used in many areas.

Matlab uses solvers, possible numerical methods for solving ODEs. Solvers implement the following methods for solving systems of differential equations.

TABLE I. Methods

It is proposed to write the system of differential equations written above in the Matlab language format and use the ode113 solver for solving, since this solver gives the most accurate result among all those considered [28, 29].

\section{DEVELOPMENT OF SOFTWARE MODULES AND} CONDUCTING A SIMULATION EXPERIMENT

For this, two files are created with the extension ".m". One file is responsible for directly solving systems of equations for the three upper vertebrae of the thoracic spine. The second file visualizes the results and draws graphs.

Here is a part of the program:

$\%$ designation of variables

tim $=[04]$

$u 0 T 1=-0.0171$

$u 0 T 2=-0.0236$

u0T3 = -0.0305

u0T4 = -0.0356

$w 0 T 1=0.5413 ;$

$w 0 T 2=0.503$

$w 0 T 3=0.481$

$w 0 T 4=0.462$

fiOT1 $=\operatorname{atan}((u 0 T 2-u 0 T 1) /(w 0 T 2-w 0 T 1))$;

fiOT2 $=\operatorname{atan}((u 0 T 3-u 0 T 2) /(w 0 T 3-w 0 T 2)) ;$

fiOT3 $=\operatorname{atan}((u 0 T 4-u 0 T 3) /(w 0 T 4-w 0 T 3))$

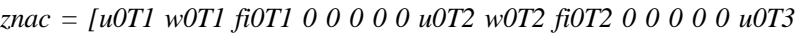
w0T2 fiOT3 000 ol;

$h 2=0.2 ;$ 
\% launch solver

$[T, X]=$ ode113(@(t,y)diffurVer6(t,y),tim,znac);

$\%$ visualization

figure(1);

$\operatorname{subplot}(2,3,1), \operatorname{plot}(T, X(:, 1))$

hold on

$\operatorname{subplot}(2,3,1), \operatorname{plot}(T, X(:, 2))$

$\operatorname{subplot}(2,3,1), \operatorname{plot}(T, X(: ; 3))$

$\operatorname{subplot}(2,3,1), \operatorname{plot}(T, X(:, 4))$

hold off

grid on

The harmonic effect was applied to the lower vertebra in the form of longitudinal force.

Typical results of mathematical modelling are presented in Figure 2. It is also of interest to consider the ratio of a forward-backward shift to an up-down shift. To do this, three more graphs are built in the second window (Figure 3).
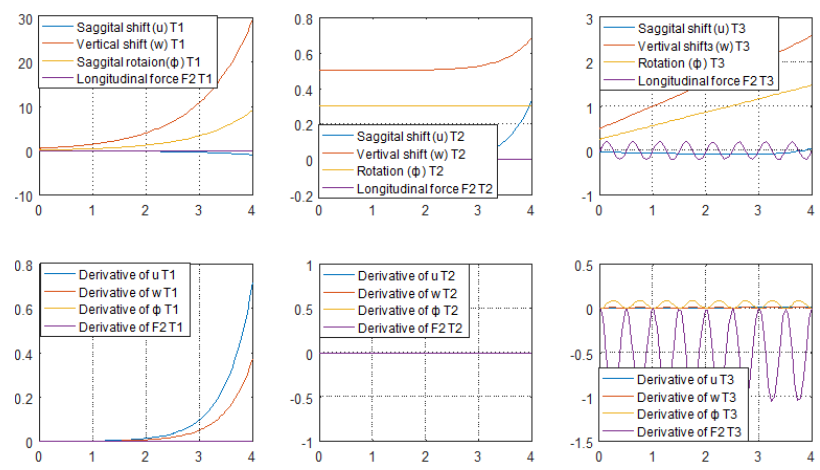

Fig. 2. The results of solving systems of equations
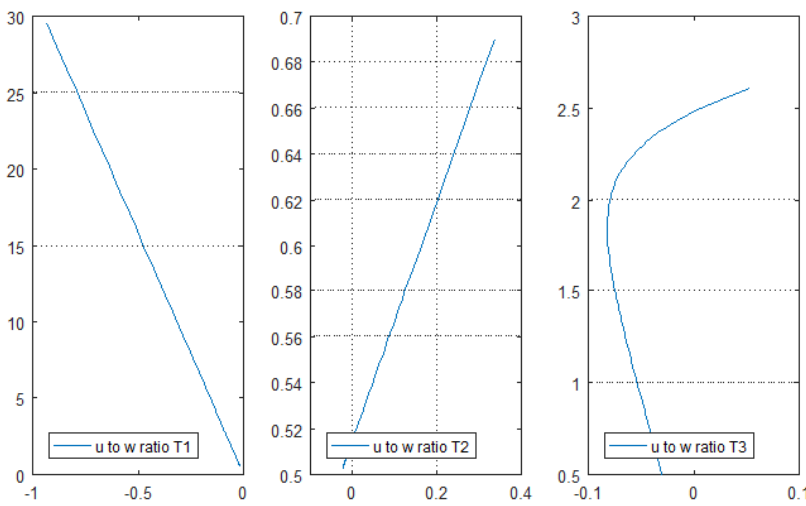

Fig. 3. The results of the conclusion of the relations $u$ to $w$ for each vertebra

A tool has been obtained that allows one to study the evolution of the centers of three vertebrae interconnected when applying standard exposure. Forcing forces that implement step and harmonic functions are considered as standard. In this example, a harmonic effect was used. Examples of parameter evolution over a short time interval are shown in Figures 2 and 3.

\section{VIII.CONCLUSION AND RESEARCH PROSPECTS}

A tool has been obtained that allows one to study the evolution of the centers of three vertebrae interconnected when applying standard exposure. Forcing forces that implement step and harmonic functions are considered as standard. In this example, a harmonic effect was used. Examples of parameter evolution over a short time interval are shown in Figures 2 and 3.

In the course of work, the tasks were completed. A structural diagram of the three upper vertebrae of the thoracic spine was constructed using the Orne-Liu system. A system of 21 differential equations corresponding to the constructed structural scheme is recorded. The choice of the solver function for the implementation of system behaviour simulation in the environment of mathematical modelling Matlab is substantiated. Matlab environment implements a software tool for simulation of the selected segment of the spine, as well as simulation experiments.

The data obtained during calculations can then be applied to the already developed three-dimensional model of the thoracic spine [8], given that the system of equations will be written for all twelve vertebrae. In the future, a similar mathematical model can be applied to the entire spine, since the initial data for the cervical, thoracic and lumbar spine are calculated and can be used.

\section{ACKNOWLEDGMENT}

The reported study was funded by RFBR according to the research project № 17-48-020074.

\section{REFERENCES}

[1] Boonbrahm P., Sewata L., Boonbrahm S. Transforming 2D Human Data into 3D Model for Augmented Reality Applications: in Procedia Computer Science 75:28-33 · December 2015, DOI: 10.1016/j.procs.2015.12.193.

[2] Bennani H., McCane B., Cornwall J. Three dimensional (3D) lumbar vertebrae data set. in Data Science Journal 15(8) - August 2016, DOI: $10.5334 / \mathrm{dsj}-2016-009$.

[3] Rehm J, Germann T, Akbar M, Pepke W, Kauczor H-U, Weber M-A, et al. (2017) 3D-modeling of the spine using EOS imaging system: Inter-reader reproducibility and reliability. PLoS ONE 12(2): e0171258. https://doi.org/10.1371/journal.pone.0171258.

[4] Aroeira R.M.C., Pertence A.E.M., Kemmoku D.T., Greco M. Threedimensional geometric model of the middle segment of the thoracic spine based on graphical images for finite element analysis. in Journal of Digital Imaging 29(2) - November 2015, DOI: 10.1007/s10278-015-9841-1.

[5] Picazo ML, Baro A., Barquero LMD, Di Gregorio S., Martelli Y., Romera J., Steghofer M., Ballester MAG, Humbert L. 3-D SubjectSpecific Shape and Density Estimation of the Lumbar Spine From a Single Anteroposterior DXA Image Including Assessment of Cortical and Trabecular Bone. // IEEE transactions on medical imaging, 2018, No. 37 (12), 2651-2662 pp.;

[6] Hollenbeck J.F.M., Cain C.M., Fattor J.A., Rullkoetter P.J., Laz P.J. Statistical shape modeling characterizes three-dimensional shape and alignment variability in the lumbar spine. // Journal of biomechanics, 2018, No. 69, 146-155 p.

[7] Pat. 2445919 Russian Federation, IPC51 A 61 B 5/103 Method for assessing spinal deformity using the 3D scanner computer complex / Tsykunov M. B., Kuleshov A. A., Andreev S. V., Vetrile M. S .; Applicant (s) and patent holder (s) Federal State Institution Central Research Institute of Traumatology and Orthopedics named after N. N. Priorov Rosmedtehnologii - No. 2009144013; declared 11/30/09; publ. 03/27/12, Bull. No. 9 - 12 pp .: ill.;

[8] Nikonova, A.I. Development of a 3D model of the musculoskeletal system using the example of the human thoracic spine (in Russian) / Biotechnical, medical, environmental systems and robotic systems - 
Biomedical systems-2018: Sat. tr XXXI Vseros. scientific and technical conf. Stud., pier. scientists and special. / under total. ed. IN AND. Zhuleva. - Ryazan: IP Konyakhin A.V. (Book Jet), 2018 .-- p. 32-35;

[9] Voinea G.-D., Butnariu S., Mogan G. Measurement and geometric modeling of human spine posture for medical rehabilitation purposes using a wearable monitoring system based on inertial sensors. in Sensors 17(1) · January 2017, DOI: 10.3390/s17010003

[10] Guan W., Sun Y., Qi X., Hu Y., Duan C., Tao H., Yang X. Spinal biomechanics modeling and finite element analysis of surgica instrument interaction. Comput Assist Surg (Abingdon). 2019 Jan 28:1-9. doi: 10.1080/24699322.2018.1560086.

[11] Meyer F., Humm J., Purushothaman Y., Willinger R., Pintar F.A., Yoganandan N. Forces and moments in cervical spinal column segments in frontal impacts using finite element modeling and human cadaver tests. // Journal of the mechanical behavior of biomedical materials, 2019, No. 90, 681-688 p.;

[12] Fan Ruoxun, Liu Jie, Liu Jun, and Wang Weijun, "Presentation of an Approach on Determination of the Natural Frequency of Human Lumbar Spine Using Dynamic Finite Element Analysis," Applied Bionics and Biomechanics, vol. 2019, Article ID 5473891, 8 pages, 2019. https://doi.org/10.1155/2019/5473891.

[13] Pourahmadi M.R., Takamjani I., Jaberzadeh S., Sarrafzadeh J., Sanjari M.A., Bagheri R., Taghipour M. Kinematics of the spine during sit-to-stand movement using motion analysis systems: A systematic review of literature. J Sport Rehabil. 2018 Oct 13:1-17. doi: $10.1123 /$ jsr.2017-0147.

[14] Pat. 2271147 Russian Federation, IPC51 A 61 B 5/11 Method for registering biomechanical properties of the spine and device for its implementation / Bakusov L. M., Nasyrov R. V., Minasov T. B.; applicant (s) and patent holder (s) L. M. Bakusov, R. V. Nasyrov, T. B. Minasov - No. 2004114960/14; declared 05/17/04; publ. 03/10/06, Bull. No. 7. - 11 pp .: ill.;

[15] Pat. 2272563 Russian Federation IPC51 A 61 B 5/103 Method for examining the musculoskeletal system in the sagittal plane using topographic photometry / Tsykunov M. B., Malakhov O. A., Eryomushkin M. A., Fedorova S. A.; Applicant (s) and patent holder (s) of the ГУН Central Scientific Research Institute of Traumatology and Orthopedics named after N.N. Priorov, Ministry of Health of the Russian Federation - No. 2004123951; declared 08/06/04; publ. 03/27/06, Bull. No. 9. - 7 pp .: ill.;

[16] Bakusov L. M., Nasyrov R. V., Minasov T. B. Application of the method of functional biomechanical tests to study the condition of the human spine (in Russian)// Mechatronics. M.: New Technologies, 2001, No. 6. S. 17 - 23 p.;
[17] Bayoglu R., Geeraedts L., Groenen K.H. J., Verdonschot N., Koopman B., Homminga J. Twente spine model: A complete and coherent dataset for musculoskeletal modeling of the thoracic and cervical regions of the human spine. // Journal of biomechanics, 2017, No. 58, 52-63 p.;

[18] Badamshin R.A., Bakusov L.M.,.Nasyrov R.V, Minasov T.B. A method for diagnosis of biomechanical characteristics of the spinal column// Meditsinskaia tekhnika, 2007, №5, 41(3): pp.3-8, DOI: 10.1007/s10527-007-0021-6.

[19] Jakubicek R., Chmelik J., Jan J., Ourednicek P., Lambert L., Gavelli G. Fully Automatic CAD System for Spine Localization and Vertebra Segmentation in CT Data. // World congress on medical physics and biomedical engineering 2018, No. 68 (1), 223-226 p.;

[20] Buharbaeva L.Ya., Nasyrov R.V., Tiunov I.S. Classification and structure of biomedical computer-aided design systems (Article in Russian) Med. Tekh. 2015 May-Jun;(3):41-5.

[21] Dubrovsky, V. I., Fedorova, V. N. Biomechanics (in Russian)/ V. I. Dubrovsky, V. N. Fedorova. - M .: Vlados-Press, 2008 .-- 672 p.: Ill.;

[22] Ilyasov, L. V. Biomedical measuring equipment: Textbook. A manual for universities (in Russian)/ L.V. Ilyasov. - M .: Higher. Shk., 2007 .- 342 p.: Ill.;

[23] Popov, G.I., Samsonova, A.V. Biomechanics of motor activity (in Russian)/ G.I. Popov, A.V. Samsonova. - M .: Academia, 2014 .-320 p .: ill.;

[24] Erofeev V. I., Kazhaev V. V., Semerikova N. P. Waves in the rods. Dispersion. Dissipation. Nonlinearity (in Russian). - $\mathrm{M}$.: FIZMATLIT, 2002 .-- 208 p.;

[25] Samples, I.F. Optimal biomechanical systems (in Russian)/ / I.F. Obraztsov, M.A. Khanin. - M.: Medicine, 1989. -272 p.;

[26] Review of programs for symbolic mathematics. [Electronic resource]. URL: https://compress.ru/article.aspx?id=16152

[27] MATLAB. [Electronic resource]. URL: https://www.mathworks.com;

[28] Nikonova, A.I. The solution of the second-order differential equation for forced oscillations and the construction of frequency characteristics in the mathematical modeling environment MATLAB (in Russian)/ Molodejny Vestnik UGATU. Technical science. - Ufa: RIC USATU, 2019 .-- No. 1 (20) - p. 138-141;

[29] Badilatti S.D., Kuhn G.A., Ferguson S.J., Müller R. Computational modeling of bone augmentation in the spine. Journal of Orthopaedic Translation, Volume 3, Issue 4, October 2015, Pages 185-196. https://doi.org/10.1016/j.jot.2015.09.003 